\title{
Combining fasting plasma glucose and glycosylated haemoglobin improved the accuracy for detecting patients with diabetes
}

\author{
Anand SS, Razak F, Vuksan Vet al. Diagnostic strategies to detect glucose intolerance in a multiethnic population. Diabetes \\ Care 2003;26:290-6.
}

Sources of funding: not stated.

For correspondence: Dr S S Anand,

McMaster University, Hamilton, $O N$,

Canada.

anands@mcmaster.ca

Abstract and

commentary also

appear in ACP Journal

Club.

\begin{abstract}
QUESTION: In a multiethnic cohort randomly assembled in Canada, is a combination of fasting plasma glucose (FPG) and glycosylated haemoglobin $\left(\mathrm{HbA}_{1 \mathrm{c}}\right)$ more accurate than FPG alone for diagnosing impaired glucose tolerance (IGT) and diabetes?
\end{abstract}

\section{Design}

Optimal diagnostic criteria using FPG, 2 hour post glucose load plasma glucose, and $\mathrm{HbA}_{1 c}$ to identify patients with IGT and diabetes were determined (using the 1998 WHO diagnostic criteria as the "gold standard") and

compared. Cut points were determined from receiver operating characteristic curves.

\section{Setting}

3 cities in Canada.

\section{Participants}

936 Canadians of South Asian, Chinese, and European descent.

\begin{tabular}{lllll} 
for detecting patients with diabete & $\begin{array}{l}\text { Sensitivity } \\
\text { ( } 95 \% \mathrm{Cl})\end{array}$ & $\begin{array}{l}\text { Specificity (CI) } \\
\text { Test (cut point) }\end{array}$ & +LR (Cl) & -LR (Cl) \\
\hline $\mathrm{FPG}(\geq 5.7 \mathrm{mmol} / \mathrm{l})$ & $83 \%(74$ to 93$)$ & $88 \%(86$ to 90$)$ & $7(6$ to 8$)$ & $0.2(0.1$ to 0.3$)$ \\
\hline $\mathrm{HbA}_{1 \mathrm{c}}(\geq 5.9 \%)$ & $75 \%(64$ to 86$)$ & $79 \%(76$ to 82$)$ & 4 (3 to 4$)$ & $0.3(0.2$ to 0.5$)$ \\
\hline $\begin{array}{l}\mathrm{FPG}(\geq 5.7 \mathrm{mmol} / \mathrm{l}) \\
\begin{array}{l}\text { and } \mathrm{HbA} \\
(\geq 5.9 \%)\end{array}\end{array}$ & $72 \%(60$ to 83$)$ & $95 \%(94$ to 96$)$ & $14(10$ to 19$)$ & $0.3(0.2$ to 0.4$)$ \\
\hline
\end{tabular}

${ }^{*}$ Diagnostic terms defined in glossary; LRs and $\mathrm{Cl}$ calculated from data in article.

\section{COMMENTARY}

In the study by Anand $e$ al, the overall sensitivity of fasting glucose (American Diabetes Association recommendations) for diagnosing diabetes was low (48\%). A dual cut point of FPG $\geq 5.7 \mathrm{mmol} / \mathrm{l}$ and $\mathrm{HbA}_{1 c} \geq 5.9 \%$ had a sensitivity of $72 \%$ and a specificity of $95 \%$, and in South Asian people $85 \%$ and $91 \%$, respectively.

In clinical practice, we prefer to know which patients with normal or impaired FPG have diabetes according to the oral glucose tolerance test (OGTT). Patients with cardiovascular risk factors and increased risk of mortality cluster in this group. ${ }^{1-2}$ If they have abnormal glucose metabolism, different follow up and management may be required. In patients with FPG $<7.0 \mathrm{mmol} / \mathrm{l}$, can we limit further work up for diabetes to those at high risk of diabetes, or with cardiovascular risk factors or impaired FPG? Because of the burden of screening a large population we have no other choice, although in certain populations the FPG levels might miss a small percentage of patients with diabetes. If we decide to continue beyond determination of FPG levels, do we offer an OGTT, determination of $\mathrm{HbA}_{1 c}$, or close follow up with repeated determinations of FPG? OGTT may offer better sensitivity and specificity for development of macrovascular and microvascular complications of diabetes. Besides the high cost, $\mathrm{HbA}_{1 \mathrm{c}}$ measurement requires additional testing to evaluate its performance.

Although the question about screening does not have clear cut answers, some conclusions may be drawn: Firstly, persons with normal or impaired FPG should be stratified according to their risk of diabetes. Factors to consider include ethnic origin, obesity, and family history. A formal index should be developed and validated for that purpose. Secondly, persons at high risk of diabetes and cardiovascular morbidity should be closely followed even if FPG is normal. Thirdly, the decision to use OGTT, or a combination of FPG values and $\mathrm{HbA}_{1 \mathrm{c}}$ or close follow up depends on the local population, as well as the cost of the tests. Fourthly, serious and continuous effort should be made in these patients to modify risk factors and maintain healthy life styles.

Leonard Leibovici, MD Rabin Medical Centre Petah Tizva, Israel

1 Consequences of the new diagnostic criteria for diabetes in older men and women. DECODE Study (Diabetes Epidemiology: Collaborative Analysis of Diagnostic Criteria in Europe). Diabetes Care 1999;22:1667-71.

2 Harris TJ, Cook DG, Wicks PD, et al. Impact of the new American Diabetes Association and World Health Organisation diagnostic criteria for diabetes on subjects from three ethnic World Heaps living in the UK. Nutr Metab Cardiovasc Dis 2000;10:305-9.
grous

\section{Description of tests and diagnostic}

\section{standard}

FPG and 2 hour post glucose load (ie, after ingestion of $75 \mathrm{~g}$ of oral glucose) plasma glucose were measured using enzymatic methods with a hexokinase reference. $\mathrm{HbA}_{1 c}$ was analysed using high performance liquid chromatography. The 1998 WHO diagnostic criteria were used as the "gold standard" to classify the participants into 3 categories: normal $(\mathrm{FPG}<7.0$ $\mathrm{mmol} / \mathrm{l}$ and a $2 \mathrm{~h}$ glucose $<7.8 \mathrm{mmol} / \mathrm{l}$ ), IGT (FPG $<7.0 \mathrm{mmol} / \mathrm{l}$ and a $2 \mathrm{~h}$ glucose $7.8-11.0 \mathrm{mmol} / \mathrm{l}$ ), or diabetic (FPG $\geq 7.0 \mathrm{mmol} / \mathrm{l}$ or a 2 hour glucose $\geq 11.1$ mmol/l). The American Diabetes Association criteria were also applied, and participants were classified into the 3 categories: normal (FPG $<6.1 \mathrm{mmol} / \mathrm{l}$ ), impaired fasting glucose (FPG $6.1-6.9 \mathrm{mmol} / \mathrm{l})$, or diabetic (FPG $\geq 7.0 \mathrm{mmol} / \mathrm{l})$

\section{Main outcome measures}

Sensitivity and specificity, and positive and negative likelihood ratios.

\section{Main results}

According to WHO criteria, $6.4 \%$ and $15.2 \%$ of participants had diabetes and IGT, respectively. FPG and $\mathrm{HbA}_{1 c}$ optimal cut points, with the corresponding sensitivity and specificity and positive and negative likelihood ratios for diagnosing diabetes, are in the table; combining FPG and $\mathrm{HbA}_{1 \mathrm{c}}$ improved the specificity and positive likelihood ratio (table). The American Diabetes Association criteria had a sensitivity of $48 \%$ (95\% CI 36 to 61$)$ for diagnosing diabetes. FPG or $\mathrm{HbA}_{1 \mathrm{c}}$ alone or in combination did not yield satisfactory diagnostic properties for diagnosing IGT.

\section{Conclusion}

In a multiethnic cohort randomly assembled in Canada, a combination of fasting plasma glucose and glycosylated haemoglobin had greater specificity and positive likelihood ratio than fasting plasma glucose alone for diagnosing diabetes. 